\title{
Determination of Anodized Aluminum Material Characteristics by Means of Nanoindentation Measurements
}

\author{
Maria Datcheva $^{1}$, Sabina Cherneva ${ }^{1}$, Maria Stoycheva ${ }^{2}$, Roumen Iankov ${ }^{1^{*}}$, Dimitar Stoychev $^{3}$ \\ ${ }^{1}$ Institute of Mechanics, Bulgarian Academy of Sciences, Sofia, Bulgaria; ${ }^{2}$ Institute of Electrochemistry and Energy Systems, Bul- \\ garian Academy of Sciences, Sofia, Bulgaria; ${ }^{3}$ Institute of Physical Chemistry, Bulgarian Academy of Sciences, Sofia, Bulgaria. \\ Email: *iankovr@yahoo.com
}

Received June $27^{\text {th }}, 2011$; revised July $26^{\text {th }}, 2011$; accepted August $11^{\text {th }}, 2011$.

\begin{abstract}
An aluminium $A D-3$ has been anodized under four different conditions, namely at low temperature $\left(-5^{\circ} \mathrm{C}\right)$, room temperature $\left(25^{\circ} \mathrm{C}\right)$, with and without sealing the anodized coating in boiling distilled water. The solution used for formation of alumina layer in all cases was an electrolyte containing $180 \mathrm{~g} / \mathrm{l}$ sulphuric acid at a constant forming voltage (voltastatic anodizing). In order to assess the mechanical properties of the obtained anodic alumina layers a series of nanoindentation tests was performed employing different indentation procedures. The two mechanical characteristics of the alumina films, the indentation hardness $\left(H_{I T}\right)$ and the indentation modulus $\left(E_{I T}\right)$, were determined by means of the instrumented indentation and the Oliver \& Pharr approximation method. All measurements were done on Agilent G200 Nanoindenter fitted with a diamond Berkovich type tip. Time dependent effects were investigated by tests with different peak hold time and different loading rate. The change of the mechanical properties with indentation depth was also examined. The effect of the working temperature during the growth of the alumina layers and the influence of the pore sealing on the mechanical properties are evaluated via comparison of the average load-displacement curves. The role of the temperature of the electrolyte and the sealing process during the formation of the alumina films, with respect to possible changes of their chemical composition and structure, are discussed in order to explain the observed differences in the measured load-displacement curves and the determined $H_{I T}$ and $E_{I T}$.
\end{abstract}

Keywords: Thin Films, Alumina, Mechanical Properties, Nanoindentation

\section{Introduction}

Alumina is the most wide used oxide ceramic material. Basic applications of alumina are for/as a protective and wear-resistant films, filler for plastics, sunscreens, carrier layers in converters for gas purification, CD/DVD polishing, etc. Alumina is used in dentistry as alternative to the sodium bicarbonate for patients that have high blood pressure, as well as in medicine for hip replacement. The technology utilizing aluminum oxide detector material for radiation dose measurement is at the core of many dosimeter systems and services. Other applications of alumina coatings are for protection against corrosion, in optoelectronics and etc. The basic characteristics of alumina, which are important for these applications, are the high compression and electrical strength, high hardness, resistance to abrasion and to chemical attacks by a wide range of chemicals, high thermal conductivity, resistance to thermal shocks, high degree of refractoriness, etc.

Because of the wide field of application of alumina and because of the fact, that usually the mechanical properties of the thin films are very different from the mechanical properties of the bulk materials, we selected anodic alumina films as a subject of our research on assessing the mechanical properties by means of instrumented nanoindentation.

The alumina layers are also an interesting model system for investigation of physical characteristics and mechanical properties because the anodically formed $\mathrm{Al}_{2} \mathrm{O}_{3}$ layers, depending of the temperature of formation, are characterized with quite different thickness, structure, porosity, micro-hardness and wear resistance. In the same time their chemical composition practically remains unchanged. 
Mechanical properties of pure aluminium are well known [1-3], but there are very few data in literature about mechanical properties of anodic alumina films, [4-7] and this was an additional motivation for performing nanoindentation tests in order to determine the alumina mechanical properties. Since Oliver and Pharr promoted in 1992 the method for determining mechanical properties of materials by instrumented indentation techniques [8], this method has been widely adopted for characterization of the mechanical behaviour of materials at small scales. Its attractiveness stems largely from the fact that mechanical properties can be determined directly from indentation load and displacement measurements without the need to image the indentation impresssion. With high-resolution testing equipment, this facilitates the determination of properties at the micrometer and nanometre scales [9-11]. For this reason the method has become a primary technique for determining the mechanical properties of thin films without removing the film from the substrate and as well as for capturing small structural features [12-29]. Nanoindentation technique nowadays is applied for characterisation of thin films prepared from metals, polymers, rubber-like materials [30] and soft materials.

The aim of the presented here work is to assess the effect of the temperature of the working electrolyte during the anodic formation of porous alumina and the influence of the pore sealing on the mechanical properties of the alumina layers. In the present work different indentation programs are applied in order to determine the indentation hardness $\left(H_{I T}\right)$ and the indentation modulus $\left(E_{I T}\right)$ of the alumina layers.

\section{Theoretical Part}

Indentation experiments had been traditionally used to measure hardness of materials. The method of Oliver and Pharr (1992) is used to determine the indentation hardness $\left(H_{I T}\right)$ and indentation modulus $\left(E_{I T}\right)$ of materials from indentation load-displacement data obtained during one cycle of loading and unloading. This technique involves a number of simplifying assumptions: 1) the specimen is an infinite deformable half-space; 2) the indenter has an ideal geometry; 3) the material is linerelastic; 4) pile-up is negligible, and 5) there are no interaction surface forces during contact such as adhesion or friction forces [31-35].

A schematic representation of a typical data set obtained with a Berkovich indenter is presented in Figure 1, where the parameter $P$ designates the load and $h-$ the indentation depth relative to the initial undeformed sample surface.

There are three important quantities that can be obtained from the $P$ - $h$ curves: 1$)$ the maximum load $P_{\max } ; 2$ )

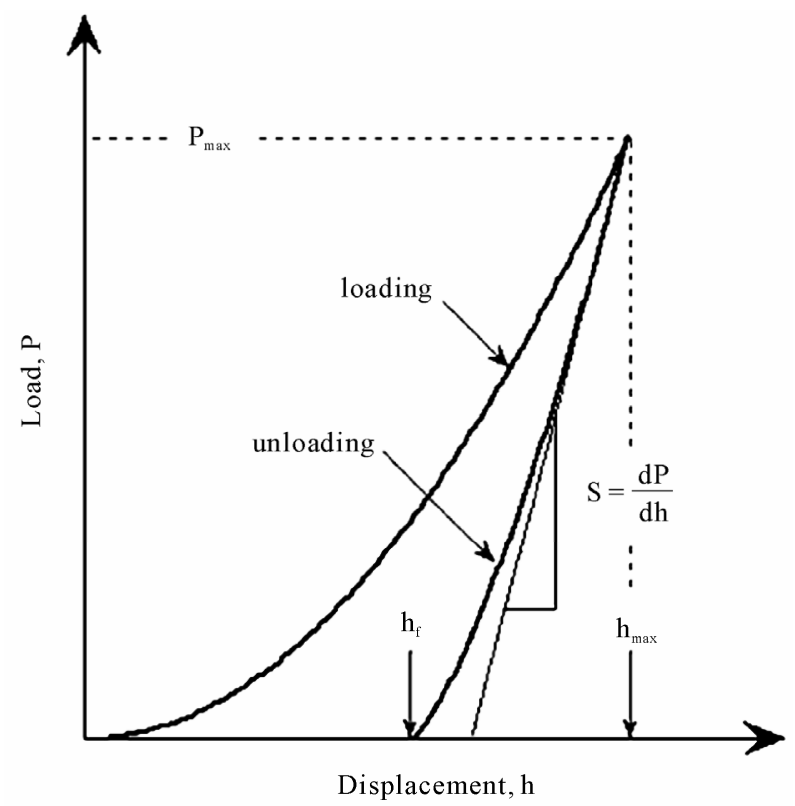

Figure 1. Schematic illustration of indentation load-displacement data showing important measured parameters $[36]$.

the maximum displacement $h_{\max }$ and 3) the elastic unloading stiffness. The unloading stiffness or the so called the contact stiffness is defined as the slope $S=\mathrm{d} P / \mathrm{d} h$ of the upper portion of the unloading curve during the initial stages of unloading.

The exact procedure used to determine $H_{I T}$ and $E_{I T}$ is based on the unloading processes shown schematically in Figure 2, in which it is assumed that the behaviour of the Berkovich type indenter can be modelled by a conical indenter with a half-included angle $\phi=70.3^{\circ}$ that gives the same depth-to-area relationship as the Berkovich indenter.

Letting $A\left(h_{c}\right)$ be an "area function" that describes the projected area of the indenter at a distance $h_{c}=h_{\max }-$ $h_{s}$. Once the contact area is determined, the indentation hardness is calculated from the maximum force divided by the projected area:

$$
H_{I T}=\frac{P_{\max }}{A\left(h_{c}\right)} .
$$

The indentation modulus can be determined by:

$$
E_{I T}=\frac{\left(1-v^{2}\right)}{\left\{\frac{2 \beta \sqrt{A\left(h_{c}\right)}}{S \sqrt{\pi}}-\frac{1-v_{i}^{2}}{E_{i}}\right\}},
$$

where $\beta$ is a correction factor, whose value depends on the indenter geometry (for Berkovich indenter $\beta=1.03$ is adopted), $v$ is the Poisson's ratio of the probe, $E_{i}$ and 


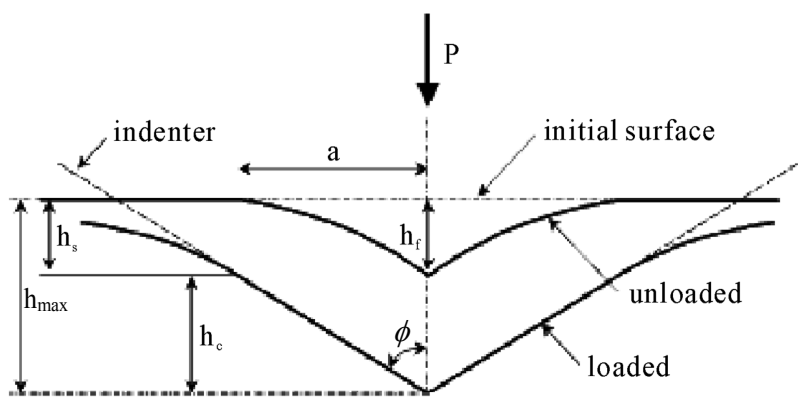

Figure 2. Schematic illustration of the unloading process showing parameters characterizing the contact geometry [36].

$v_{i}$ are the indenter's elastic parameters [36].

\section{Experimental Part}

\subsection{Deposition of Alumina Films}

Four different alumina films of $9.5 \mu \mathrm{m}$ thickness were deposited on $2000 \mu \mathrm{m}$ thick AD-3 aluminium substrate. The chemical composition of the AD-3 substrate is: $99.67 \% \mathrm{Al}$ and $0.33 \% \mathrm{Fe}$. The deposition process was performed in anodizing bath of $180 \mathrm{~g} / 1 \mathrm{H}_{2} \mathrm{SO}_{4}$ Merck electrolyte at a constant forming voltage of $20 \mathrm{~V}$ and it was lasting 40 minutes (voltastatic anodizing). The electrolyte's temperature for samples 27 and 28 was $-5^{\circ} \mathrm{C}$, while for samples 31 and 14 it was $25^{\circ} \mathrm{C}$. Samples 28 and 14 were kept after anodizing 1 hour in a bath of distilled water at temperature $100^{\circ} \mathrm{C}$ aiming this way to seal the alumina pores. Samples description is given in Table 1.

\subsection{Nanoindentation Experiments}

Nanoindentation experiments reported hereafter were realized by Agilent G200 Nano-indenter. The nano-tester is fitted with a Berkovich three-sided diamond pyramid with centerline-to-face angle of $65.3^{\circ}$ and $20 \mathrm{~nm}$ radius at the tip of the indenter. The minimum load possible to be applied is $10 \mathrm{mN}$, and the maximum load is $500 \mathrm{mN}$. Displacement recording resolution is $0.01 \mathrm{~nm}$ and the load recording resolution is $50 \mathrm{nN}$. The device is equipped with an optical microscope with 2 objectives of magnification $\times 250$ and $\times 1000$, respectively.

We decided to realize series of 25 indentations on each sample probe in order to have better statistics (see Figure 3). There are several pre-existing indentation methods provided by the Agilent Technologies and for the purposes of our study we chose the following three methods described in more details below: Method A (fixed maximum displacement), Method B (fixed maximum load) and Method C (loading with force control).

\subsubsection{Method A}

This method prescribes a single load/unload cycle to a specified depth. Hardness and modulus are determined using the stiffness as calculated from the slope of the load-displacement curve during unloading.

In the frame of this method the indenter tip begins approaching the surface from a distance (Surface Approach Distance) above the surface of approximately $1000 \mathrm{~nm}$. Because of the high roughness of the samples, used in this study, we had to increase the Surface Approach Distance from the default to $5000 \mathrm{~nm}$.

The approach velocity is determined by Surface Approach Velocity parameter. When the device determines

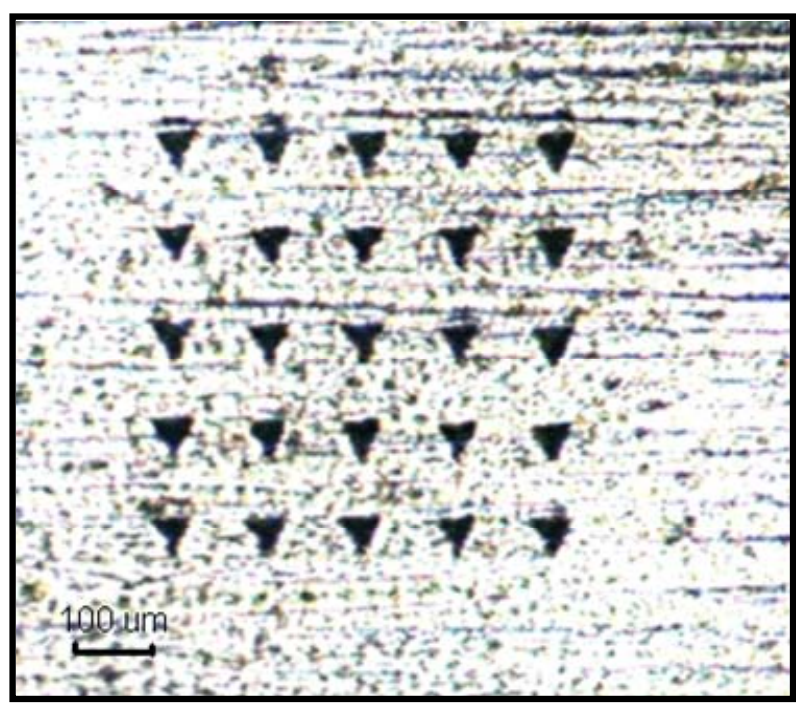

Figure 3. Residual imprints of sample $29(\times 250)$.

Table 1. Investigated materials.

\begin{tabular}{|c|c|c|c|c|c|c|}
\hline Sample No. & Materials & Thickness $[\mu \mathrm{m}]$ & Electrolyte type & Electrolyte $\mathrm{T}\left[{ }^{\circ} \mathrm{C}\right]$ & Anodization regime & Sealing \\
\hline 27 & $\mathrm{Al}_{2} \mathrm{O}_{3} / \mathrm{Al}$ & $9.5 / 1990.5$ & $180 \mathrm{~g} / 1 \mathrm{H}_{2} \mathrm{SO}_{4}$ (Merck) & -5 & $20 \mathrm{~V}$ for $40 \mathrm{~min}$ & NO \\
\hline 28 & $\mathrm{Al}_{2} \mathrm{O}_{3} / \mathrm{Al}$ & $9.5 / 1990.5$ & $180 \mathrm{~g} / 1 \mathrm{H}_{2} \mathrm{SO}_{4}$ (Merck) & -5 & $20 \mathrm{~V}$ for $40 \mathrm{~min}$ & YES \\
\hline 29 & Al AD-3 & 2000 & N/A & $\mathrm{N} / \mathrm{A}$ & $\mathrm{N} / \mathrm{A}$ & N/A \\
\hline 31 & $\mathrm{Al}_{2} \mathrm{O}_{3} / \mathrm{Al}$ & $9.5 / 1990.5$ & $180 \mathrm{~g} / 1 \mathrm{H}_{2} \mathrm{SO}_{4}$ (Merck) & 25 & $20 \mathrm{~V}$ for $40 \mathrm{~min}$ & NO \\
\hline 14 & $\mathrm{Al}_{2} \mathrm{O}_{3} / \mathrm{Al}$ & $9.5 / 1990.5$ & $180 \mathrm{~g} / 1 \mathrm{H}_{2} \mathrm{SO}_{4}$ (Merck) & 25 & $20 \mathrm{~V}$ for $40 \mathrm{~min}$ & YES \\
\hline
\end{tabular}


that it has contacted the test surface, according to the criteria Surface Approach Sensitivity (Table 2), the indenter penetrates the surface at a rate determined by Strain Rate Target (Table 2). When the surface penetration reaches the Depth Limit (Table 2), the load on the indenter is held constant for Peak Hold Time (Table 2). The load on the indenter is then reduced by an amount defined by Percent to Unload (Table 2) at a rate equal to the maximum loading rate. Then the indenter is held in contact with the sample under constant force for $75 \mathrm{sec}-$ onds. Finally, the indenter is withdrawn from the sample completely and the sample is moved into position for the next test [37].

Input parameters for method A are given in Table 2. We realized series of nanoindentation experiments with $1500 \mathrm{~nm}$ maximum displacement and $1 \mathrm{~s}$ peak hold time. Moreover we realized nanoindentation experiments with $3000 \mathrm{~nm}$ maximum displacement at $1 \mathrm{~s}, 10 \mathrm{~s}$ and $20 \mathrm{~s}$ peak hold time.

As a result we obtained the load-displacement curves, indentation hardness and modulus for each of the investigated alumina films at two different depths and for various peak hold time.

\subsubsection{Method B (G-Series Load, Displacement and Time)}

This method prescribes a single load-unload cycle. No properties are calculated from the load-displacementtime information. We used this method to compare loaddisplacement curves of the films at fixed maximum load.

During realization of this method the indenter tip begins approaching the surface from a distance above the surface of approximately Surface Approach Distance (Table 2). The velocity is determined by Surface Approach Velocity parameter (Table 2). When the indenter contacts the test surface, according to the criteria Surface Approach Sensitivity (Table 2), the single load/unload cycle begins. The indenter penetrates the surface at a rate defined by Maximum Load/Time to Load (Table 2). Loading is terminated when the Load on Sample reaches Maximum Load (Table 2). The load on sample is then held constant for ten seconds. Then the indenter is withdrawn completely at a rate that is twice as fast as the loading rate.

Input parameters for method B are given in Table 2. We realized series of nanoindentation experiments by

Table 2. Input parameters.

\begin{tabular}{|c|c|c|c|c|}
\hline Parameter & Unit & Method A & Method B & Method C \\
\hline Percent to Unload & $\%$ & 90 & 90 & 90 \\
\hline Surface Approach Velocity & $\mathrm{nm} / \mathrm{s}$ & 10 & 25 & 10 \\
\hline Depth Limit & $\mathrm{nm}$ & $1500 / 3000$ & N/A & N/A \\
\hline Delta $X$ for Finding Surface & $\mu \mathrm{m}$ & -50 & -50 & -50 \\
\hline Delta $Y$ for Finding Surface & $\mu \mathrm{m}$ & -50 & -50 & -50 \\
\hline Strain Rate Target & $1 / \mathrm{s}$ & 0.05 & 0.05 & $\mathrm{~N} / \mathrm{A}$ \\
\hline Allowable Drift Rate & $\mathrm{nm} / \mathrm{s}$ & 0.05 & 0.05 & 0.05 \\
\hline Perform Drift Test Segment & - & 1 & 1 & N/A \\
\hline Approach Distance to Store & $\mathrm{nm}$ & 1000 & 1000 & 1000 \\
\hline Peak Hold Time & $\mathrm{s}$ & $1 / 10 / 20$ & N/A & $20 / 200$ \\
\hline Surface Approach Distance & $\mathrm{nm}$ & 5000 & 5000 & 5000 \\
\hline Surface Approach Sensitivity & $\%$ & 40 & 40 & 40 \\
\hline Poisson's Ratio & - & 0.3 & 0.3 & 0.3 \\
\hline Maximum load & gf & N/A & 20 & 50 \\
\hline Time to load & $\mathrm{s}$ & N/A & 30 & 15 \\
\hline Number of times to load & - & 1 & 1 & 10 \\
\hline
\end{tabular}


method B at fixed maximum load of 20 gf $(\approx 196 \mathrm{mN})$ and 10 seconds peak hold time. As a result we obtained load-displacement curves for each of the investigated alumina films.

\subsubsection{Method C (G-Series Basic Hardness, Modulus, Tip Cal, Load Control)}

This method prescribes a series of load/unload cycles in a single indentation experiment. Indentation hardness and modulus are determined using the stiffness as calculated from the slope of the load-displacement curve during each unloading cycle. The indenter tip approaches the surface at a rate of Surface Approach Velocity (Table 2) starting from a distance above the surface of about Surface Approach Distance (Table 2). When the indenter senses the surface, according to the criteria Surface Approach Sensitivity (Table 2), the cyclical loading/unloading algorithm begins. For each cycle $i$, the indenter penetrates the surface at a rate defined by (Maximum Load/Time to Load $)^{*}\left(2^{\wedge} i / 2^{\wedge}\right.$ Number of Times to Load $)$. Loading for the cycle ends when the Load on Sample reaches Maximum Load $*\left(2^{\wedge} i / 2^{\wedge}\right.$ Number of Times to Load). At the peak load for the cycle, the Load on Sample is held constant for a period equal to Peak Hold Time (Table 2). Then, the indenter is withdrawn at a rate defined by Load Rate Multiple for Unload * Loading Rate until the Load on Sample reaches Percent to Unload* Load Limit (Table 2). This load/unload process is repeated, incrementing $i$ for each cycle, until $i$ reaches Number of Times to Load (Table 2). After the last load/ unload cycle, the Load on Sample is held constant for 75 seconds. The indenter is then withdrawn completely and the sample is moved into position for the next test.

Input parameters for method $\mathrm{C}$ are given in Table 2. We realized series of nanoindentation experiments by method $\mathrm{C}$ at fixed maximum load of $50 \mathrm{gf}$ and with 20 and 200 seconds peak hold times and 10 cycles.

\subsection{SEM and EDS Analysis}

Scanning electron microscopy (SEM) investigation was performed on JEOL JSM 6390 apparatus equipped with INCA energy-dispersive X-ray spectrometer (EDS). It has been done in order to better understand the structure changing of the alumina layers and to better visualize the imprints and the surrounding area because in some cases the resolution of the optical device of the nanotester was not sufficient to recognize the imprint images. EDS analysis/spectrum of the investigated specimens only gives a rough indication (in atomic\%) since the electron beam does not have enough high spatial resolution (Ø $1 \mu \mathrm{m}$ and few $\mu \mathrm{m}$ depth) to analyze each particle individually. The SEM pictures were performed in the SEI regime.

\subsection{Determination of the Surface Roughness}

The roughness of investigated alumina films was measured by means of Perthometer C3A ("Mahr Perthen", Germany), equipped with recorder Perthograph C40 ("Mahr Perthen", Germany). Test section $I_{t}$ (the section which pin of the perthometer pass during one measurement) for all measurements was $5 \mathrm{~mm}$. We used vertical magnification 500:1 and horizontal magnification $20: 1$. As a result we determined the average roughness $R_{a}$ and the mean roughness depth $R_{z}$ of samples 28 and 14. The definitions of $R_{a}$ and $R_{z}$ read:

$$
\begin{gathered}
R_{a}=\frac{1}{I_{m}} \int_{0}^{I_{m}}|y| \mathrm{d} x \\
R_{z}=\frac{1}{5}\left(Z_{1}+Z_{2}+Z_{3}+Z_{4}+Z_{5}\right),
\end{gathered}
$$

with $y(x)$-profile ordinates of the roughness profile; $I_{m}$ measured section length (this part of test section length $I_{t}$, which we evaluate); $Z_{i},(i=1, \cdots, 5)$ is the vertical distance between the highest peak and the deepest valley within $i$-th sampling length of five consecutive single measured sections. The results are given in Table 3 and they show that sample 28 has higher roughness compared to sample 14 .

\section{Results}

As a result of nanoindentation experiments, we obtained load-displacement curves for each of the alumina samples and after that by means of Oliver \& Pharr method the indentation hardness $H_{I T}$ and indentation modulus $E_{I T}$ were calculated by the software available as part of the Agilent G200 Nanoindenter. The comparison between load-displacement curves obtained by means of method $A$ at $1500 \mathrm{~nm}$ indentation depth and $1 \mathrm{~s}$ peak hold time is shown in Figure 4 for samples 27 and 28, and in Figure 5 for samples 14 and 31 . The outcome of this comparison is that the treatment of the sample anodized at $-5^{\circ} \mathrm{C}$ with boiling water does not much influence its mechanical properties. On the contrary, the sealing of pores by means of a bath at $100^{\circ} \mathrm{C}$ distilled water for the alumina film obtained at $25^{\circ} \mathrm{C}$ electrolyte's temperature influences essentially its mechanical response; e.g. the $H_{I T}$ of sample 14 is higher than the indentation hardness of sample 31 .

Table 3. Roughness measures of samples 14 and 28.

\begin{tabular}{ccc}
\hline Roughness measure & Sample 14 & Sample 28 \\
\hline$R_{a}[\mu \mathrm{m}]$ & 0.32 & 0.48 \\
$R_{z}[\mu \mathrm{m}]$ & 2.5 & 3.9 \\
\hline
\end{tabular}




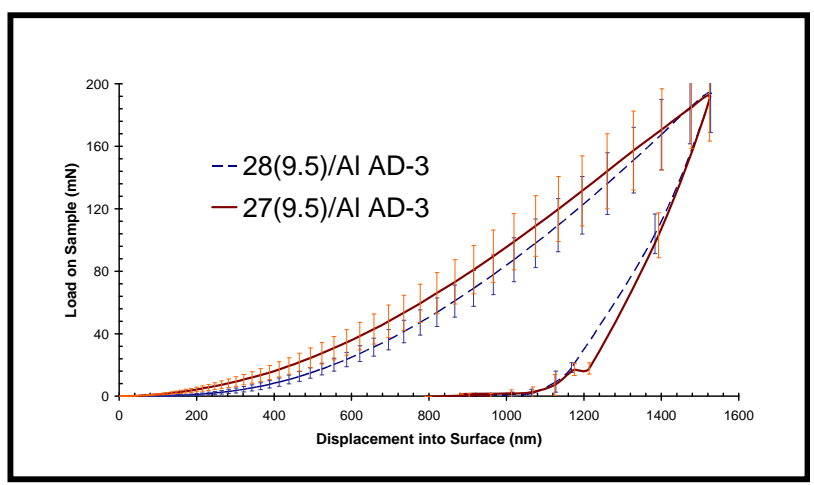

Figure 4. Sample average sheets for samples 28 and 27, test method A1500/1.

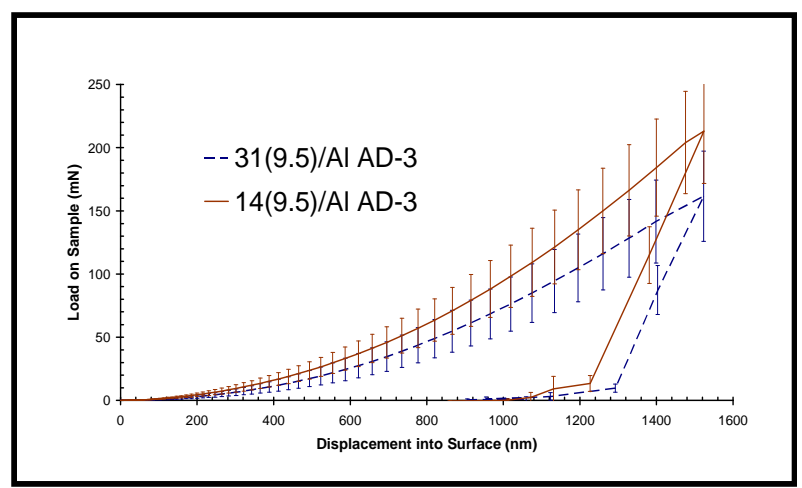

Figure 5. Sample average sheets for samples 31 - 14, test method A1500/1.

A comparison between $H_{I T}$ and $E_{I T}$, obtained as a result of 25 indentations via method A with depth limit 1500 $\mathrm{nm}(\mathrm{A} 1500 / 1)$ and $3000 \mathrm{~nm}(\mathrm{~A} 3000 / 1)$ and pick hold time $1 \mathrm{~s}$ for samples $31,14,27,28$ and 29 is shown respectively in Figures 6 and 7. The numbers given aside the symbols of each of the experimental series show the average maximum load in $\mathrm{mN}$ for this series (larger values of the maximum load correspond to the data obtained via method A3000/1).

The results show that the apparent indentation hardness of the film-substrate system is over 4 times larger than the hardness of the bulk sample from pure aluminum (see Figure 6, sample 29).

It is evident that pore sealing leads to increasing the $H_{I T}$ and $E_{I T}$ of the alumina, obtained at $25^{\circ} \mathrm{C}$ electrolyte's temperature and does not influence the characteristics of the film, obtained at $-5^{\circ} \mathrm{C}$ electrolyte's temperature.

Figures 8(a) and (b) show a comparison between the load-displacement curves of sample 28 , for two different maximum indentation depths, namely $1500 \mathrm{~nm}$ and 3000 $\mathrm{nm}(\operatorname{method} \mathrm{A})$. At larger indentation depths there is a well pronounced pop-in effect and it may be stated it occurs at $h>1500 \mathrm{~nm}$, (Figure 8(b)). Figure 8(a) shows averaged curves and therefore the pop-in effect is smeared

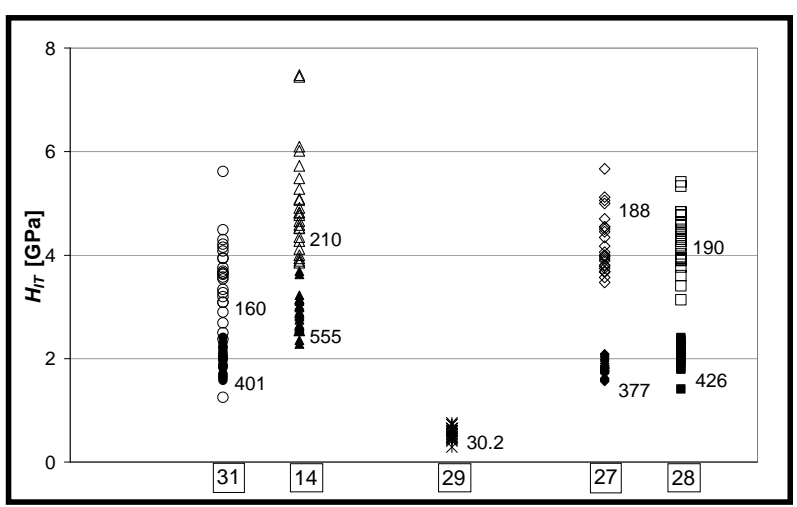

Figure 6. Calculated hardness $H$, based on test methods A1500/1 and A3000/1.

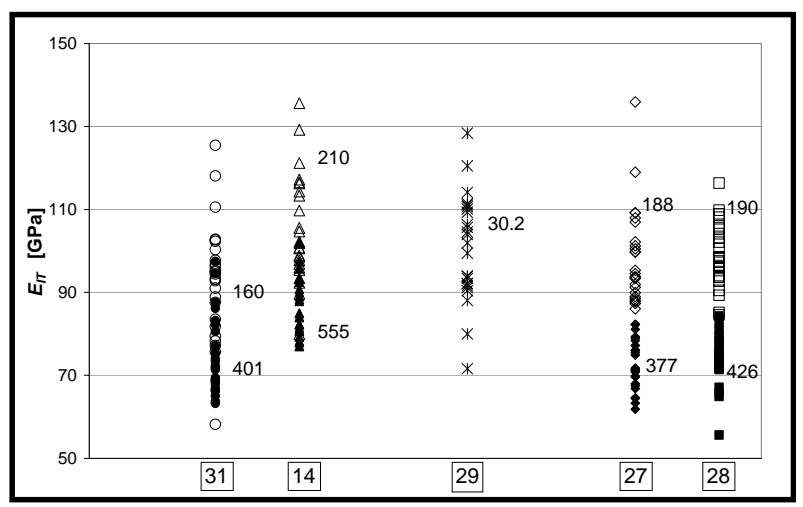

Figure 7. Calculated Young modulus E, based on test methods A1500/1 and A3000/1.

and manifested in the decrease of the slope of the loading branch of the load-displacement curve. However there may be a different reason for such decrease of the slope of load to sample - displacement into surface curve, e.g. the influence of the substrate as far as below $1500 \mathrm{~nm}$ depth the penetration exceeds $15 \%$ of the film thickness.

One significant problem with the method of Oliver and Pharr is that it does not consider a pile-up of a material around the contact impression. When pile-up occurs, the contact area is underestimated by the method and both $H_{I T}$ and $E_{I T}$ may be overestimated sometimes up to $50 \%$. Bolshakov and Pharr proposed a convenient, experimentally determined parameter that can be used to identify whether pile up is coming into the picture [38]. This parameter is the ratio of final indentation depth $h_{f}$ to the depth of the indentation at peak load, $h_{\text {max }}$. When $h_{f} / h_{\max }>0.7$ it is most possible we have a pile-up of the material around the imprint. That is why, for each sample, we calculated $h_{f} / h_{\max }$ for all 25 nanoindentations. The results are shown in Figures 9, 10, 11 and 12. It can be concluded that for samples 27 and 31 we have predominantly $h_{f} / h_{\max }>0.7$ and most probably a pile-up. For sample 31 the existence of a pile-up was proven by SEM 


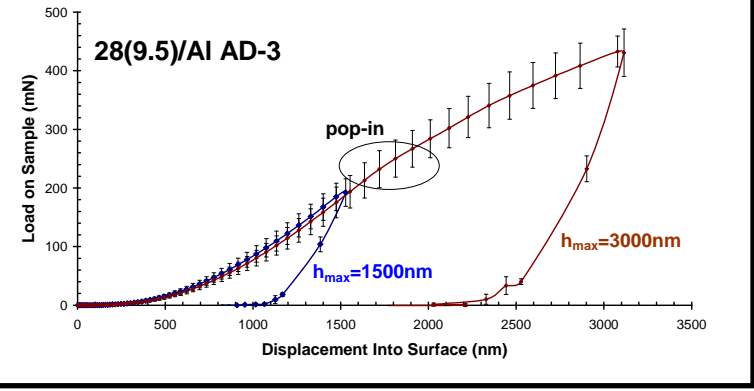

(a)

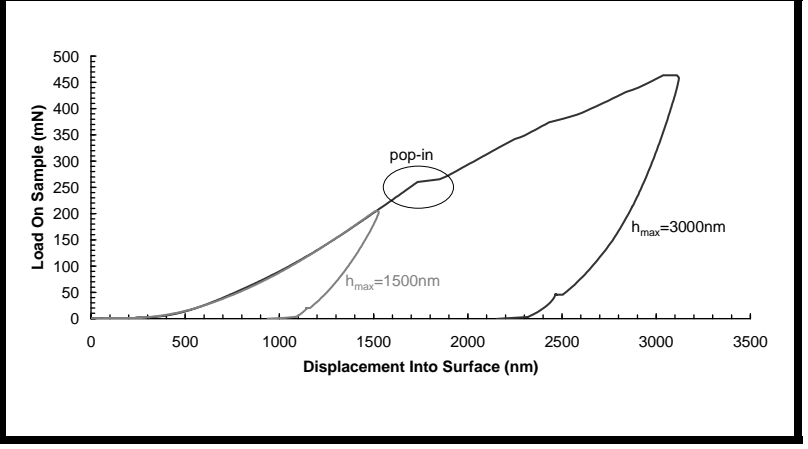

(b)

Figure 8. (a) Comparison between average load-displacement curves, obtained by methods A1500/1 and A3000/1 for sample 28; (b) an example of single load-displacement curves, obtained by methods A1500/1 and A3000/1 for sample 28.

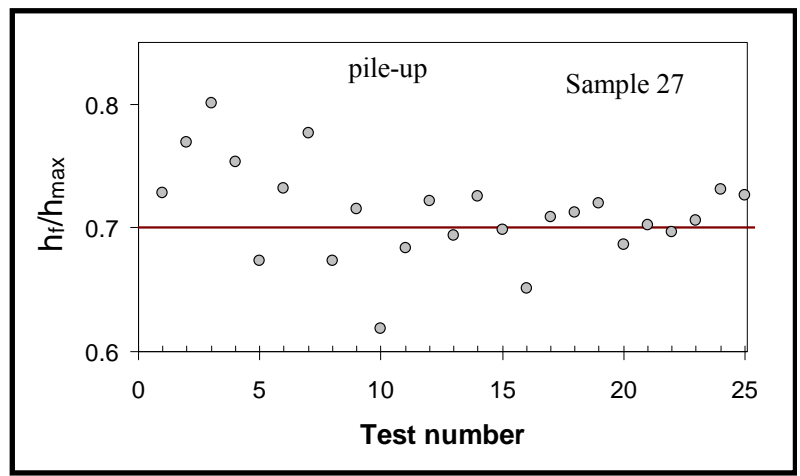

Figure 9. Determined $h_{f} / h_{\max }$ for sample 27; test method B20/10.

micrograph of a residual imprint as can be seen in Figure 13.

The creep effects at $20 \mathrm{gf}$ maximum load with $10 \mathrm{~s}$ peak hold time (Method B) are shown in Figure 14 and Figure 15, and average maximum displacements for each of the samples obtained by means of method B are given in Figure 16. Sample 31 shows the larger relative

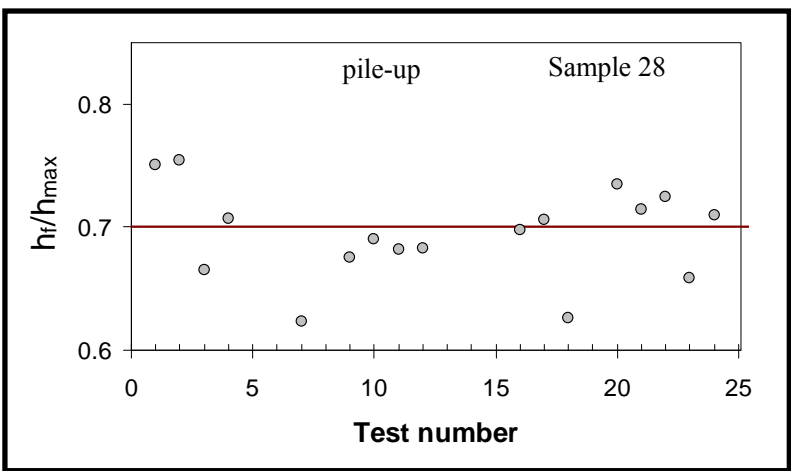

Figure 10. Determined $h_{f} / h_{\max }$ for sample 28; test method B20/10.

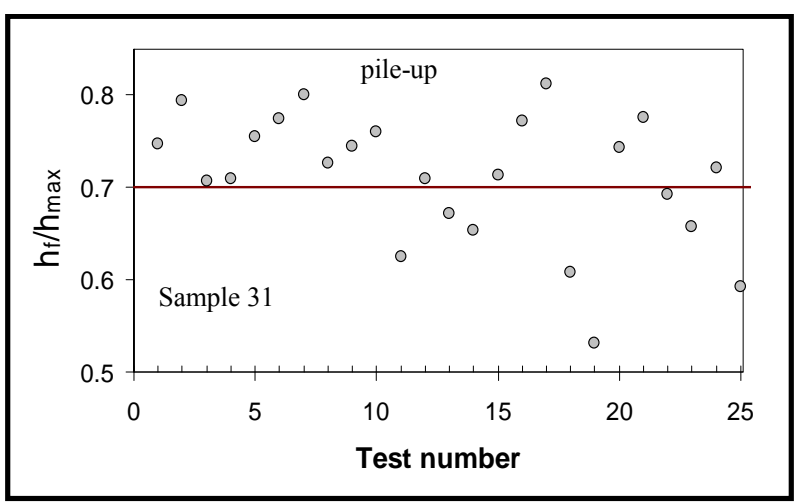

Figure 11. Determined $h_{f} / h_{\max }$ for sample 31 ; test method B20/10.

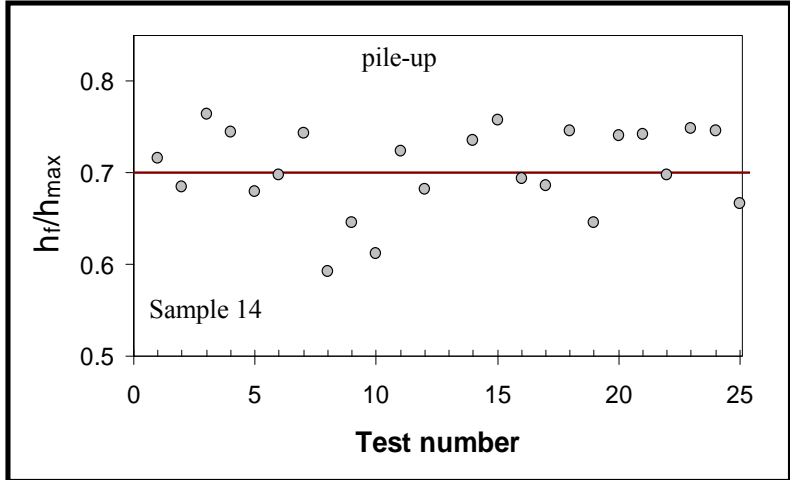

Figure 12. Determined $h_{f} / h_{\max }$ for sample 14; test method B20/10.

creep displacement $(3.4 \%)$, followed by sample 14 (3.1\%), sample $27(3.1 \%)$, sample $28(2.7 \%)$ and sample $29(2.1 \%)$, while sample 29 has the larger absolute creep displacement $(83.8 \mathrm{~nm})$, followed by sample $31(56 \mathrm{~nm})$, sample $27(51 \mathrm{~nm})$, sample $14(46 \mathrm{~nm})$ and sample 28 (43 nm).

The variation of $H_{I T}$ and $E_{I T}$ depending on depth of indentation is given in Figures 17 and 18. These two figures depict the results obtained by means of method $\mathrm{C}$ at 


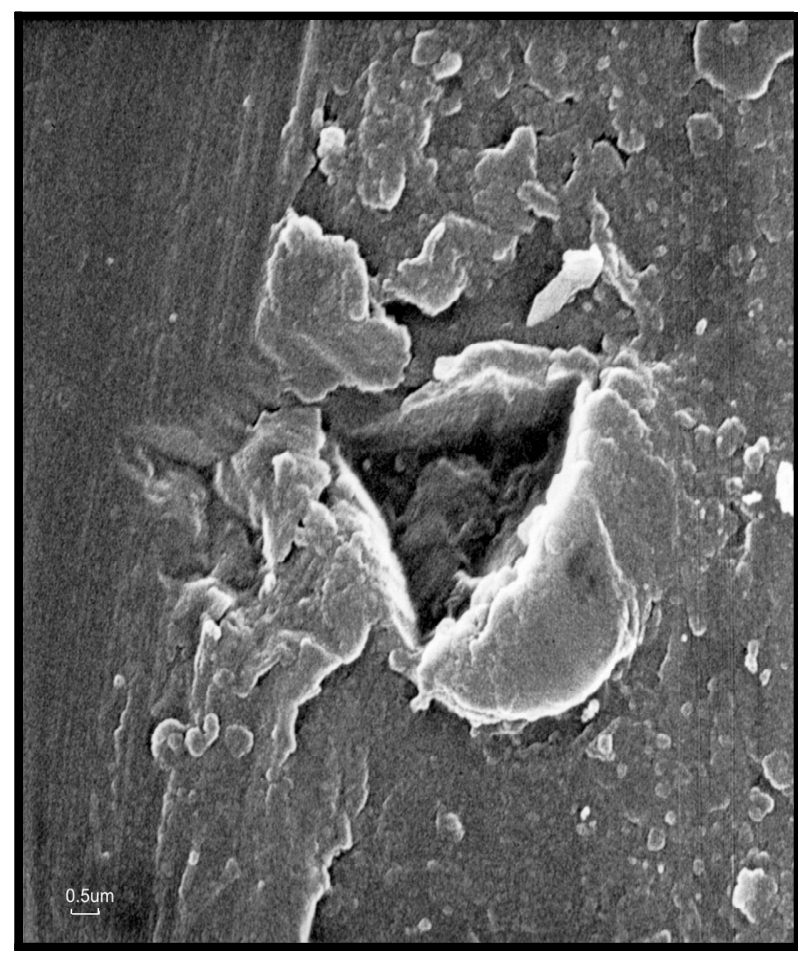

Figure 13. Residual imprint with pile up $(\times 20000$, sample 31).

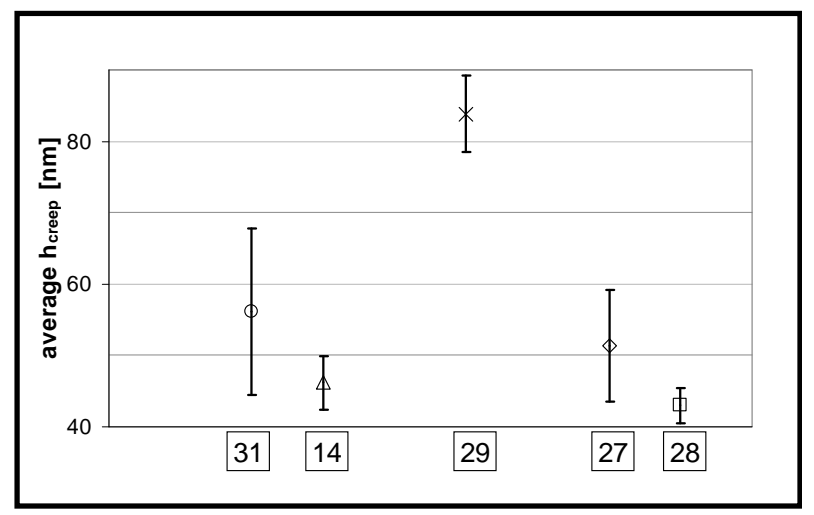

Figure 14. Comparison between average $h_{\text {creep }}$ for all samples (test B20/10).

50 gf maximum load and $20 \mathrm{~s}$ peak hold time prior each of unloading step.

It is seen that sample 14 has higher $H_{I T}$ compared to the hardness of sample 28 at the same applied maximum load (Figure 17). The same behaviour is observed for the $E_{I T}$ but the difference here is moderate (Figure 18). At the same time samples 14 and 28 have higher indentation hardness than the substrate (sample 29) and almost the same indentation modulus. Samples 14 and 28 have been sealed in boiling water and the only difference in their formation is the electrolyte's temperature during the anodization of the AD-3 substrate. However as shown in

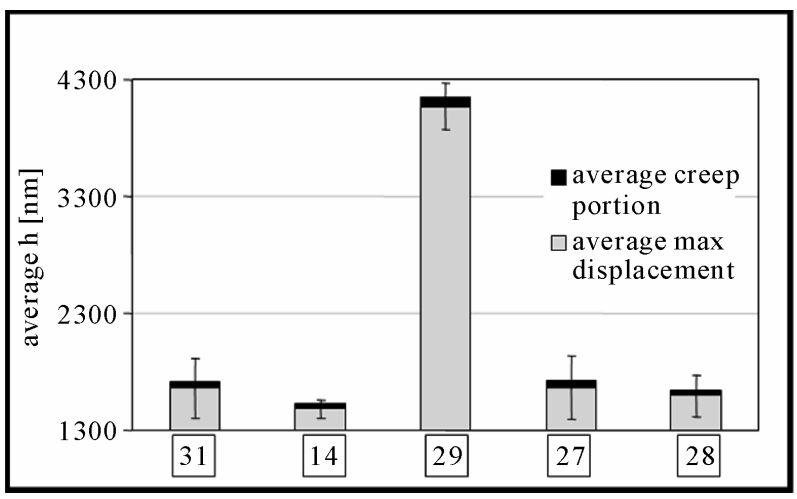

Figure 15. Comparison between average $h$ and $h_{\text {creep }}$ for all samples (test B20/10).

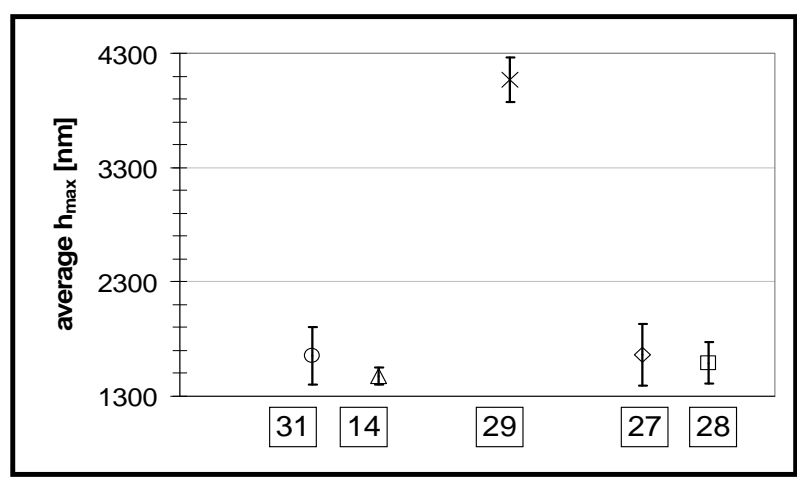

Figure 16. Average maximum displacement in test B20/10.

Table 4 the two samples have identical chemical composition, that is why we suppose that the reason for the difference in $H_{I T}$ may be due to a difference in the microstructure. The micro and nano-structute of the two alumina layers have been investigated by means of SEM image analysis. The SEI clearly shows the amorphous structure of the alumina layers. The average size of grains and pores for sample 14 are $20-30 \mathrm{~nm}$, while for sample 28 the average size of grains is $60-80 \mathrm{~nm}$, and for the pores it is $40-60 \mathrm{~nm}$. These grain and pore size values were determined in SEM regime at magnification $100000 \times$.

The comparison of $H_{I T}$ and $E_{I T}$ of sample 28 at different indentation depths and different peak hold time is shown in Figures 19 and 20. The results shown in these figures are obtained using Method $\mathrm{C}$ with 50 gf maximum load and two different values of the peak hold time $-20 \mathrm{~s}$ and $200 \mathrm{~s}$.

The same indentation method has been used to compare the $H_{I T}$ and $E_{I T}$ of sample 14 at different indentation depths and different peak hold time. The results are given in Figures 21 and 22. From the results presented in Figures 19-22 it is evident that the $H_{I T}$ and $E_{I T}$ values at one and the same maximum load are higher for the case when the peak hold time is $20 \mathrm{~s}$. 
Table 4. EDS analysis of the surface of $\mathrm{Al}_{2} \mathrm{O}_{3}$ (specimens Nos. 14 and 28).

\begin{tabular}{cccc}
\hline Element & Sample & Weight percent [\%] & Atomic percent [\%] \\
\hline O on line $K_{\alpha}$ & 14 & $54.49 \pm 0.47$ & 67.30 \\
& 28 & $53.64 \pm 0.47$ & 66.54 \\
Al on line $K_{\alpha}$ & 14 & $40.11 \pm 0.44$ & 29.38 \\
& 28 & $40.79 \pm 0.43$ & 30.01 \\
S on line $K_{\alpha}$ & 14 & $5.40 \pm 0.19$ & 3.32 \\
& 28 & $5.57 \pm 0.19$ & 3.45 \\
\hline
\end{tabular}

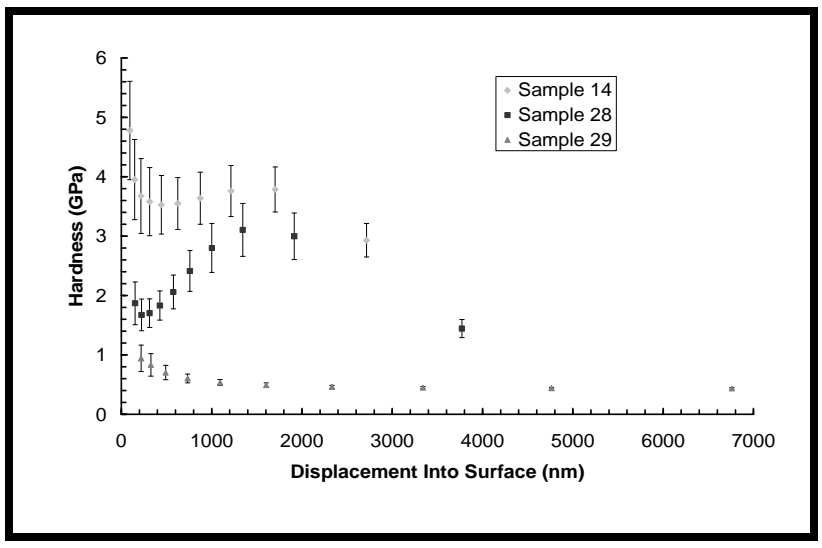

Figure 17. Comparison between indentation hardness of samples 14, 28 and 29, obtained with 20 s peak hold time by method C.

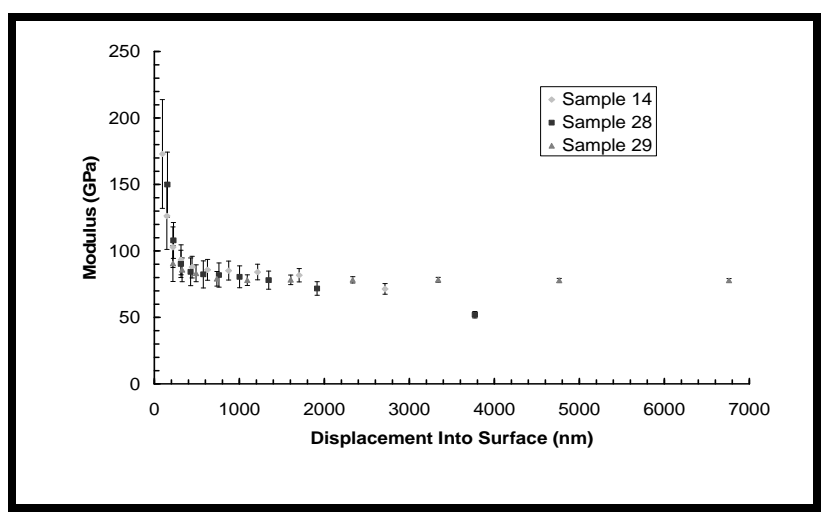

Figure 18. Comparison between indentation modulus of samples 14, 28 and 29, obtained with 20 s peak hold time by method C.

An explanation of this observation may be the effect of the creep that seems to be an inherent property of the alumina-substrate system. The SEM micrographs in Figures 23(d) and (e) show that the grain size inside the imprint, at the imprint boundary and outside the imprint is almost the same. It may be a proof that there is no grain crushing during the indentation. Figure 23(c) shows the pore structure of the alumina film (sample 28).
This is the case with the pores that seems to be closed and the volume inside the imprint may become compacted.

\section{Conclusions}

The primary intention of this study was to investigate the mechanical properties of anodized AD-3 per se and for this reason no treatment of the surface was applied. Even measurements were done on various penetration depths, the analysis presented here is using the obtained mechanical characteristics for depths exceeding $500 \mathrm{~nm}$ because of the high roughness of the alumina surface. On the other side we tried to minimize the influence of the substrate on the results and this is the reason for considering indentation depths up to $1500 \mathrm{~nm}$ (up to $15 \%$ of the aluminum oxide layer). Nevertheless the sample roughness may play significant role in our measurements. The outcome of our observation within these constraints is that the determined by means of instrumented nanoindentation test indentation hardness of anodized aluminum AD-3 varies with anodization conditions and it is over 4 times higher than the hardness of the AD-3 sample. The elastic characteristics of anodized AD-3 and the non-anodized AD-3 are almost the same, they vary in the same interval of 70 to $130 \mathrm{GPa}$ depending on the loading regime. Therefore we did not observe significant difference in the $E_{I T}$ of the different samples and we accept that the electrochemically produced $\mathrm{Al}_{2} \mathrm{O}_{3}$ layers are having almost the same $E_{I T}$ as the $\mathrm{AD}-3$.

The reactive sealing shows better results against improving the hardness when applied to sample 14 (anodized $\mathrm{AD}-3$ at $25^{\circ} \mathrm{C}$ ) over against its application to the "hard anodized" sample 28. As far as our investigation of chemical composition of samples 14 and 28 shows that they have identical chemical composition, the difference in $H_{I T}$ modulus is considered to be due to the difference in the film microstructure. This assumption was proven by SEM micrographs where we found that sample 14 has smaller grain size and pore diameter. It may be concluded that for the alumina film formed in electrolyte at 


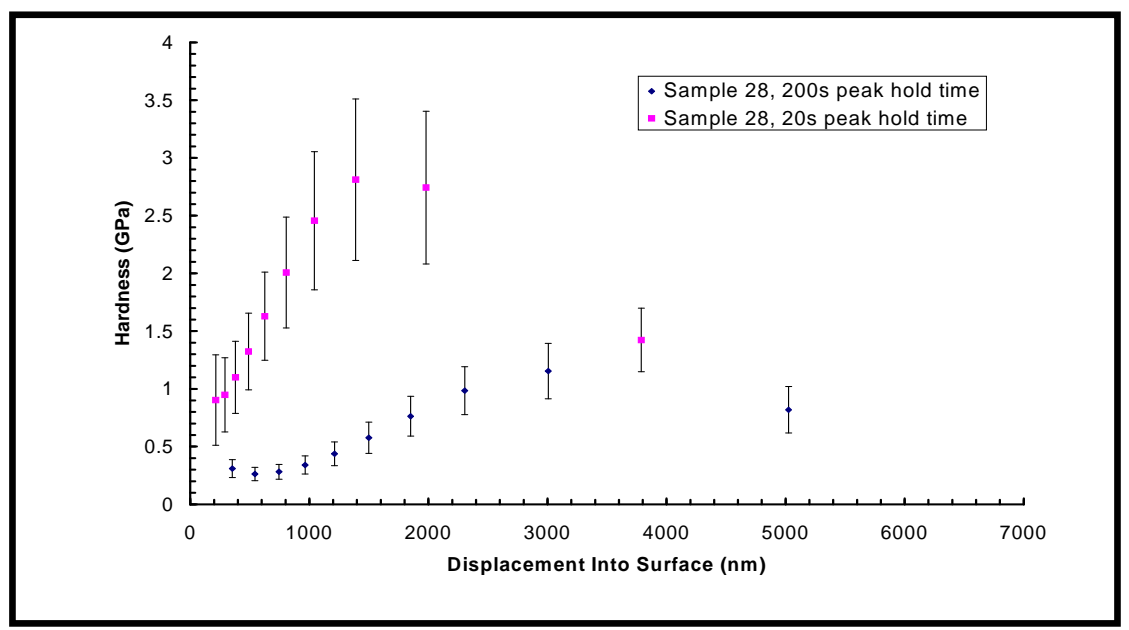

Figure 19. Comparison of $H_{I T}$ of sample 28, obtained with different peak hold time.

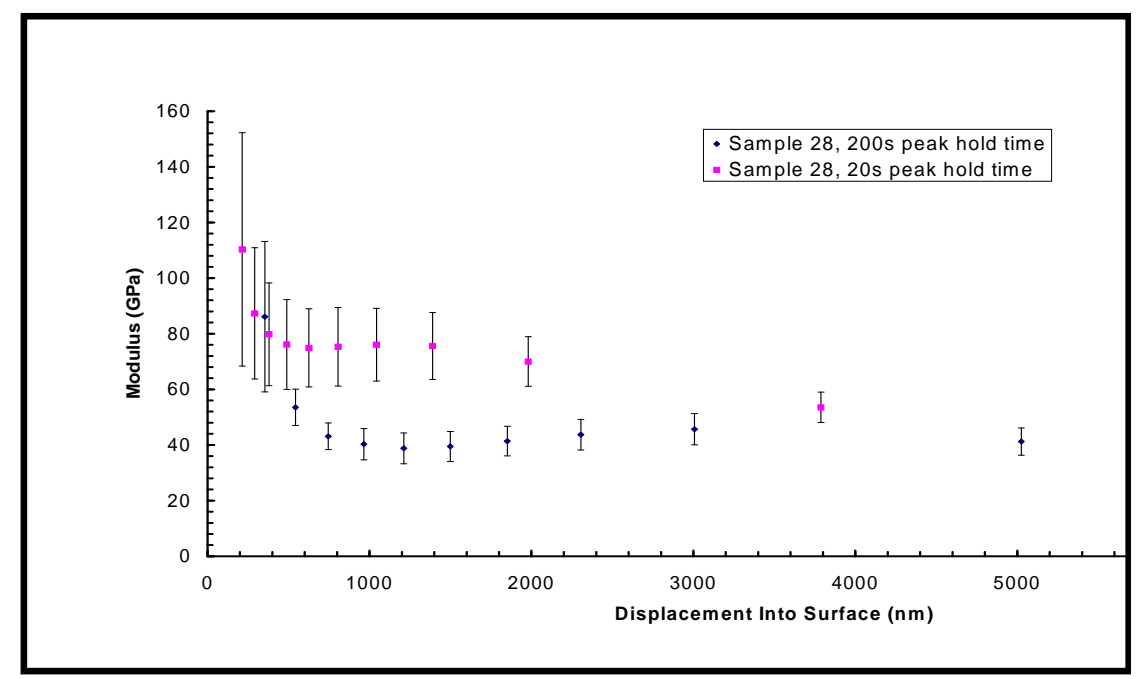

Figure 20. Comparison of $E_{I T}$ of sample 28, obtained with different peak hold time.

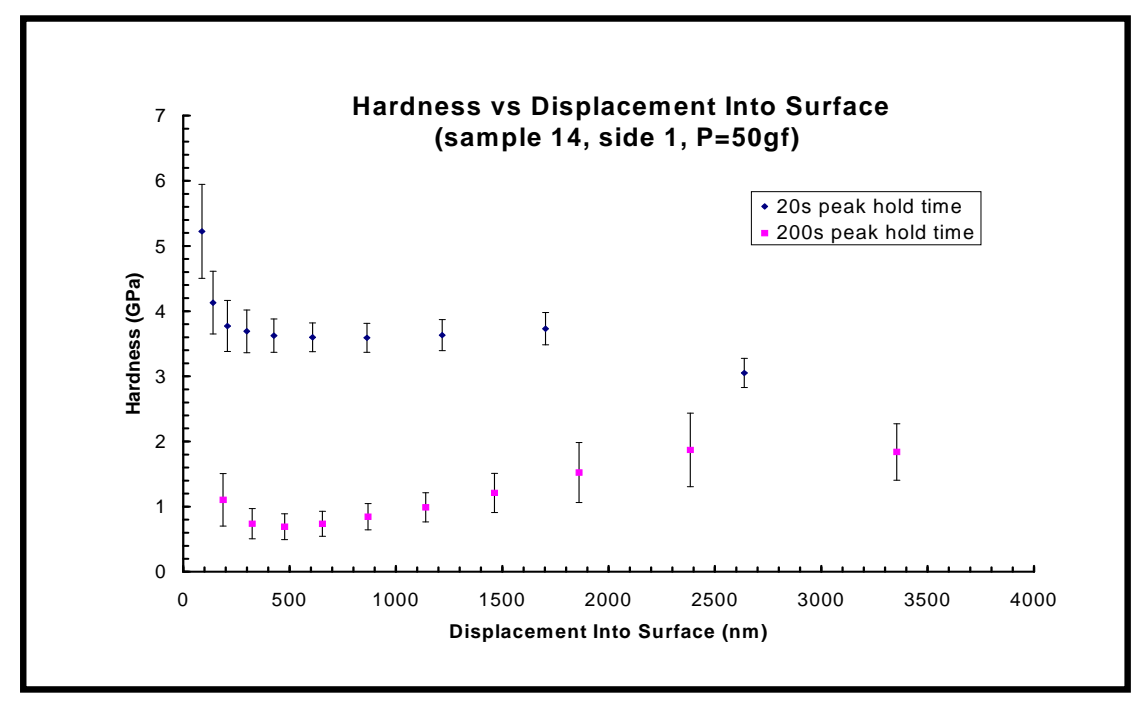

Figure 21. Comparison of $H_{I T}$ of sample 14, obtained with different peak hold time. 


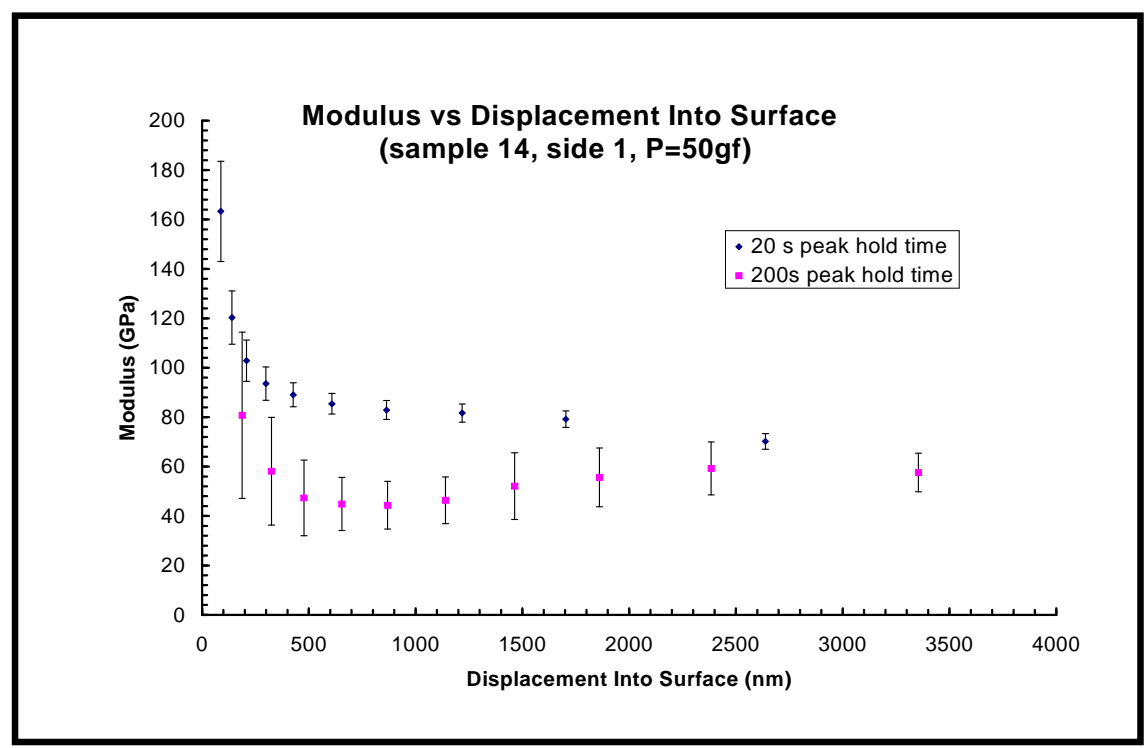

Figure 22. Comparison of $E_{I T}$ of sample 14, obtained with different peak hold time.

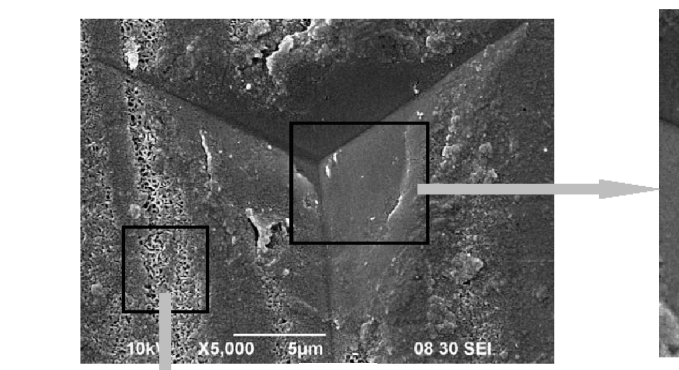

(a)

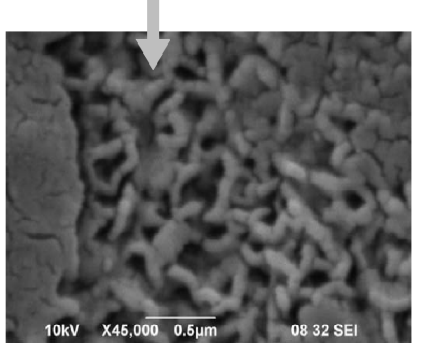

(c)

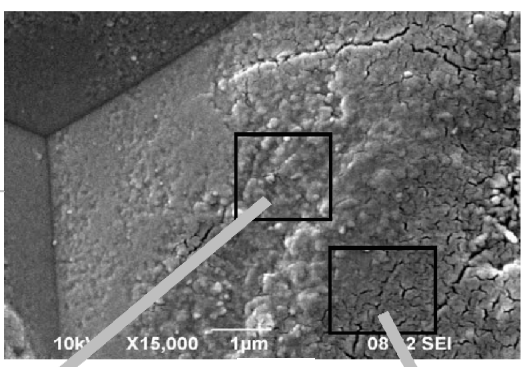

(b)

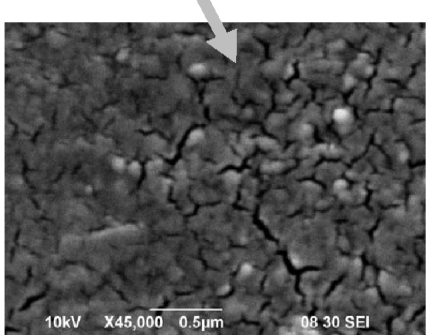

(e)

Figure 23. SEM images of the surface of sample 28, near and far from the imprint.

$-5^{\circ} \mathrm{C}$ the process of pore sealing for 1 hour in boiling water has no essential impact on the $H_{I T}$ modulus. However, for the alumina film formed at room temperature the influence of the pore sealing on the mechanical properties is noticeable. Most likely, this effect is connected with different degrees of amorphisation of the $\mathrm{Al}_{2} \mathrm{O}_{3}$ layers depending on the temperature of the electrolyte during their anodic formation.

The comparison between $H_{I T}$ and $E_{I T}$ of samples 28 and 14 derived for indentation with $20 \mathrm{~s}$ and $200 \mathrm{~s}$ peak hold time shows that $H_{I T}$ and $E_{I T}$ of these two samples are higher for the series with 20 s peak hold time, and this is most probably due to the creep of the alumina-substrate system.

At larger indentation depth (tests A with maximum depth of $3000 \mathrm{~nm}$ ) there is well pronounced pop-in effect and it firstly occurs at $h$ of approximately $1500 \mathrm{~nm}$. The analysis of the ratio $h_{f} / h_{\max }$ shows that for some of the samples it exceeds the required value for the method of Oliver and Pharr to be applicable. Therefore the obtained based on the Oliver and Pharr method $H_{I T}$ and $E_{I T}$ for samples 27 and 31 with $h_{f} / h_{\max }>0.7$ should be further approved against work hardening property as suggested in [38]. 
In order to further verify the applicability of the Oliver and Pharr method for determining $H_{I T}$ and $E_{I T}$ it is foreseen to perform a simulation of the experimental data via FE-analysis of the nano-indantation tests.

\section{Acknowledgements}

Authors gratefully acknowledge the financial support of the Bulgarian National Science Fund under grant No. TK01/0185 and of the ESF OP "Human Resources Development" under the contract BG051PO001/07/3.3-02.

\section{REFERENCES}

[1] W. Frank, G. Koch and J. Mills, "Properties of Pure Aluminum," In: J. Hatch, Ed., Aluminum: Properties and Physical Metallurgy, Vol. 1, American Society for Metals, 2005, pp. 1-24.

[2] J. Kissel and R. Ferry, "Aluminum Structures," John Wiley \& Sons, New York, 2002.

[3] T. Tsui, W. Oliver and G. Pharr, "Influences of Stress on the Measurement of Mechanical Properties Using Nanoindentation: Part I. Experimental Studies in an Aluminum Alloy," Journal of Materials Research, Vol. 11, No. 3, 1996, pp. 752-759. doi:10.1557/JMR.1996.0091

[4] F. Zhang, H. Luo and S. Roberts, "Mechanical Properties and Microstructure of $\mathrm{Al}_{2} \mathrm{O}_{3}$ /Mullite Composite," Journal of Materials Science, Vol. 42, No. 16, 2007, pp. 67986802. doi:10.1007/s10853-006-1402-z

[5] T. Sekino and K. Niihara, "Microstructural Characteristics and Mechanical Properties for $\mathrm{Al}_{2} \mathrm{O}_{3}$ /Metal Nanocomposites," NanoStructured Materials, Vol. 6, No. 5-8, 1995, pp. 663-666. doi:10.1016/0965-9773(95)00145-X

[6] T. Nieh, J. Wadsworth and O. Sherby, "Superplasticity in Metals and Ceramics," Cambridge University Press, Cambridge, 1997. doi:10.1017/CBO9780511525230

[7] D. Munz and T. Fett, "Ceramics: Mechanical Properties, Failure Behavior, Materials Selection," Springer Series in Materials Science, Vol. 36, Springer-Verlag, Berlin, 1999.

[8] W. Oliver and G. Pharr, "An Improved Technique for Determining Hardness and Elastic Modulus Using Load and Displacement Sensing Indentation Experiments," Journal of Materials Research, Vol. 7, No. 6, 1992, pp. 1564-1583.

[9] J. Pethica, R. Hutchings and W. Oliver, "Hardness Measurement at Penetration Depths as Small as $20 \mathrm{~nm}$," Philosophical Magazine A, Vol. 48, No. 4, 1983, pp. 593-606. doi:10.1080/01418618308234914

[10] F. Fröhlich, P. Grau and W. Grellmann, "Performance and Analysis of Recording Microhardness Tests," Physica Status Solidi (A), Vol. 42, No. 1, 1977, pp. 79-89.

[11] D. Newey, M. A. Wilkins and H. M. Pollock, "An U1tra-Low-Load Penetration Hardness Tester," Journal of Physics E: Scientific Instruments, Vol. 15, No. 1, 1982, pp. 119-122. doi:10.1088/0022-3735/15/1/023

[12] G. Pharr and W. Oliver, "Measurement of Thin-Film Mechanical-Properties Using Nanoindentation," MRS Bulletin,
Vol. 17, No. 7, 1992, pp. 28-33.

[13] G. Pharr, "Measurement of Mechanical Properties by Ultra-Low Load Indentation," Materials Science and Engineering A, Vol. 253, No. 1-2, 1998, pp. 151-159. doi:10.1016/S0921-5093(98)00724-2

[14] T. Shen, C. Koch, T. Tsui and G. Pharr, "On the Elastic Moduli of Nanocrystalline $\mathrm{Fe}, \mathrm{Cu}, \mathrm{Ni}$, and $\mathrm{Cu}-\mathrm{Ni}$ Alloys Prepared by Mechanical Milling/Alloying," Journal of Materials Research, Vol. 10, No. 11, 1995, pp. 28922896. doi:10.1557/JMR.1995.2892

[15] D. Stone, W. LaFontaine, O. Alexopoulos, T. Wu and C.-Y. Li, "An Investigation of Hardness and Adhesion of Sputter-Deposited Aluminum on Silicon by Utilizing a Continuous Indentation Test," Journal of Materials Research, Vol. 3, No. 1, 1988, pp. 141-147. doi:10.1557/JMR.1988.0141

[16] W. Nix, "Mechanical Properties of Thin Films," Metallurgical Transactions A, Vol. 20, No. 11, 1989, pp. 2217- 2245. doi:10.1007/BF02666659

[17] S. Hainsworth, H. Chandler and T. Page, "Analysis of Nanoindentation Load-Displacement Loading Curves," Journal of Materials Research, Vol. 11, No. 8, 1996, pp. 1987-1995. doi:10.1557/JMR.1996.0250

[18] M. Tabbal, P. Merel, M. Chaker, M. El Khakani, E. Herbert, B. Lucas and M. O'Hern, "Effect of Laser Intensity on the Microstructural and Mechanical Properties of Pulsed Laser Deposited Diamond-Like-Carbon Thin Films," Journal of Applied Physics, Vol. 85, No. 7, 1999, pp. 3860-3865. doi:10.1063/1.369757

[19] S. Hainsworth, M. McGurk and T. Page, "The Effect of Coating Cracking on the Indentation Response of Thin Hard-Coated Systems," Surface and Coatings Technology, Vol. 102, No. 1-2, 1998, pp. 97-107. doi:10.1016/S0257-8972(97)00683-X

[20] T. Tsui and G. Pharr, "Substrate Effects on Nanoindentation Mechanical Property Measurement of Soft Films on Hard Substrates," Journal of Materials Research, Vol. 14, No. 1, 1999, pp. 292-301. doi:10.1557/JMR.1999.0042

[21] T. Tsui, J. Vlassak and W. Nix, "Indentation Plastic Displacement Field: Part II. The Case of Hard Films on Soft Substrates," Journal of Materials Research, Vol. 14, No. 6, 1999, pp. 2196-2203. doi:10.1557/JMR.1999.0295

[22] S. Bec, A. Tonck, J.-M. Georges, E. Georges and J.-L. Loubet, "Improvements in the Indentation Method with a Surface Force Apparatus," Philosophical Magazine A, Vol. 74, No. 5, 1996, pp. 1061-1072. doi: $10.1080 / 01418619608239707$

[23] N. Randall, "Direct Measurement of Residual Contact Area and Volume during the Nanoindentation of Coated Materials as an Alternative Method of Calculating Hardness," Philosophical Magazine A, Vol. 82, No. 10, 2002, pp. 1883-1892. doi:10.1080/01418610208235700

[24] Y. Lim, M. Chaudhri and Y. Enomoto, “Accurate Determination of the Mechanical Properties of Thin Aluminum Films Deposited on Sapphire Flats Using Nanoindentation," Journal of Materials Research, Vol. 14, No. 6, 1999, pp. 2314-2327. doi:10.1557/JMR.1999.0308 
[25] K. Miyahara, N. Nagashima and S. Matsuoka, "Development and Application of a Combined Atomic Force Microscopy-Nanoindentation System with a Silicon Tip and a Diamond Indenter," Philosophical Magazine A, Vol. 82, No. 10, 2002, pp. 2149-2160. doi:10.1080/01418610208235724

[26] R. Saha and W. Nix, "Effects of the Substrate on the Determination of Thin Film Mechanical Properties by Nanoindentation," Acta Materialia, Vol. 50, No. 1, 2002, pp. 23-38. doi:10.1016/S1359-6454(01)00328-7

[27] J. Knapp, D. Follstaedt, S. Myers, J. Barbour and T. Friedman, "Finite-Element Modeling of Nanoindentation," Journal of Applied Physics, Vol. 85, No. 1, 1999, pp. 14601474.

[28] T. F. Page, G. M. Pharr, J. C. Hay, W. C. Oliver, B. N. Lucas, E. Herbert and L. Riester, "Nanoindentation Characterization of Coated systems: $\mathrm{P} / \mathrm{S}^{2}-\mathrm{A}$ New Approach Using the Continuous Stiffness Technique," Proceedings of Materials Research Society Symposium, Vol. 522, 1998, pp. 53-64.

[29] J. Mencik, D. Munz, E. Quandt, E. Weppelmann and M. Swain, "Determination of Elastic Modulus of Thin Layers Using Nanoindentation," Journal of Materials Research, Vol. 12, No. 9, 1997, pp. 2475-2484. doi:10.1557/JMR.1997.0327

[30] Z. Chen and S. Diebels, "Numerical Investigation of Nanoindentation of Rubber-Like Hyperelastic Layers and Parameter Re-Identification," Mechanics of Materials, 2010, In Print.

[31] I. Sneddon, "The Relation between Load and Penetration in the Axisymmetric Boussinesq Problem for a Punch of
Arbitrary Profile," International Journal of Engineering Science, Vol. 3, No. 1, 1965, pp. 47-57. doi:10.1016/0020-7225(65)90019-4

[32] A. Love, "Boussinesq's Problem for a Rigid Cone," Quarterly Journal of Mathematics, Vol. 10, No. 1, 1939, pp. 161-175. doi:10.1093/qmath/os-10.1.161

[33] A. Love, "The Stress Produced in a Semi-Infinite Solid by Pressure on Part of the Boundary," Philosophical Transactions of the Royal Society A, Vol. 228, No. 659-669, 1929, pp. 377-420. doi:10.1098/rsta.1929.0009

[34] J. Harding and I. Sneddon, "The Elastic Stresses Produced by the Indentation of the Plane Surface of a Semi-Infinite Elastic Solid by a Rigid Punch," Proceedings of the Cambridge Philosophical Society, Vol. 41, No. 1, 1945, pp. 16-26.

[35] I. Sneddon, "Fourier Transforms," McGraw-Hill, New York, 1951.

[36] W. Oliver and G. Pharr, "Measurement of Hardness and Elastic Modulus by Instrumented Indentation: Advances in Understanding and Refinements to Methodology," Journal of Materials Research, Vol. 19, No. 1, 2004, pp. 3-20. doi:10.1557/jmr.2004.19.1.3

[37] Agilent Techologies G200 Nano Indenter User's Guide, Agilent Technologies, Inc., USA, 2009.

[38] A. Bolshakov and G. Pharr, "Influences of Pileup on the Measurement of Mechanical Properties by Load and Depth Sensing Indentation Techniques," Journal of Materials Research, Vol. 13, No. 4, 1998, pp. 1049-1058. doi:10.1557/JMR.1998.0146 